\title{
Is There Such a Thing as "Least Publishable Unit”? An Empirical Investigation
}

\author{
John M. Budd \\ School of Information Science and Learning Technologies \\ University of Missouri, United States \\ buddj@missouri.edu \\ Kristine N. Stewart \\ Zayed University \\ Abu Dhabi, United Arab Emirates \\ kristine.stewart@zu.ac.ae
}

\begin{abstract}
Objective. Scientists are afflicted by what has been anecdotally referred to as the phenomenon of "Least Publishable Unit" (LPU). This project is an effort at empirical analysis of the phenomenon.

Method. Three months of the journals JAMA and the New England Journal of Medicine were analyzed to identify work that has been funded by the U.S. National Institutes of Health. Next, the database Medline was searched to discover the total number of publications by each researcher and the publications that acknowledge the single specified funding source (the grant mentioned in the journals).

Results. Biomedical researchers who published in JAMA and the New England Journal of Medicine were found to have a substantial number of publications from 2010 through 2013. Those publications are indicative of a huge literature that has to be searched in order to find work relevant to information seekers' needs. Moreover, each researcher has several publications stemming from work funded by a single NIH grant.

Contribution. The implications of this research for libraries are primarily the explosion of content and the potential duplication of publications.
\end{abstract}

\section{INTRODUCTION}

"Academic publishing has already reached a point where too much material of too little substance is being published, and this trend is continuing” (Trimble, Grody, McKelvey, \& Gad-el-Hak, 2010, p. 276). The foregoing claim is one that begs for both clarification and examination. We can take it almost as a hypothesis to be tested according to certain strictures. Before engaging in the investigation, we should note that the claim is not isolated. Goldsborough (2009) observed, "as the level of information input increases, our capacity to process and retain that information decreases" (p. 13). With these two statements we have claims about the body of literature and about people's abilities to absorb and make sense of it all. Additionally, there are cognitive and psychological—as well as time-limits to the 
development of a full understanding of the scholarly and research literature that exists. The problem is exacerbated by the annual growths of literature in every discipline. To refer to Trimble et al. (2010) again, "In short, we find the present to be inefficient, irrational, unfair, outrageously expensive, and environmentally irresponsible - in two words, unscholarly and unethical” (p. 280). Academic libraries need to become aware of the phenomenon so that services for researchers can be as completely informed as possible. Scholarly communication in general is affected by the practice. While we shall not address expense, the other topics will feature in the following analysis.

\section{LEAST PUBLISHABLE UNIT (LPU)}

There is a phenomenon that is said to typify publication in the sciences called "Least Publishable Unit” (LPU). William Broad (1981) said, "LPU is a euphemism in some circles for the fragmentation of data. A researcher publishes four short papers rather than one long one” (p. 1137). Broad and his colleague Wade (1982) included the phenomenon in a book they wrote. If they are correct, the literature of a scientific field or sub-field will be inflated. In fact, if, say, 10,000 scientists were to behave as Broad and Wade indicated, a literature of perhaps 20,000 to 30,000 papers published in a year might swell to 80,000 to 120,000 articles. Readers of the literature will then have to sift through a potentially massive number of articles in order to locate pertinent works. The amount of time required to make effective use of what is published likewise increases. The import of the effects of LPU expands beyond the individual. There are many drawbacks to rewarding large numbers of publications. Buddemeier (1981) offered, "Perhaps the most readily implemented suggestion would be to abandon the total bibliography as an evaluation tool and require applicant [for grants] to list some specific number of their most significant publications and provide a brief narrative outlining the importance of the work and the nature of the applicant's contribution” (p. 494). At this point in time, the applicants' curriculum vitae are limited in length, so the emphasis on quality should hold. "The practices of fragmented and repetitive publication are wasteful and inefficient” (Angell, 1986, p. 261). Huth (1986) added that, “The abuse of divided publication is the breaking down of findings in a single string of papers.... The research could probably be reported in a single paper. But why should the investigators confine themselves to one paper when they can slice up data and interpretations into two, three, four, five, or more papers” (p. 257).

The criticism of LPU continues across disciplines and time. Yankauer (1990) wrote, "The 'least publishable unit' (LUP)—sometimes called salami science—is perhaps the most vexing and most difficult problem to control. It arises because of pressures to publish and the institutional promotion and tenure procedures that rely on publication quantity rather than quality” (p. 400). Gleeson and Biddle (2000) pointed to another problem related to LPU: “The main worry is that duplicate, fragmented or piecemeal publications is misleading if they appear to represent independent observations. They can distort the scientific literature, especially when attempting an integration or consensus of knowledge through review articles or meta-analysis” (p. 227). Some critics get specific with their comments: "Materials containing essentially similar aims or hypotheses, data sets, conclusions, and references will likely all fall within the framework of redundant publication" (Brand, Heckman, \& Scott, 2004, p. 937). One of the most complete criticisms was provided by Dupps and Randleman (2012, pp. 1517-1518):

A number of potential consequences follow from attempts to publish multiple papers when one will suffice: 
- Dilution of quality content

- Loss of meaningful data comparisons due to sequestration of data across multiple submissions

- Over-representation of results from the same patient series in the literature

- Cost

- Reviewer fatigue

- Author fatigue

- Author sanctions

- Reader fatigue.

\section{SUPPORT FOR LPU}

It is extremely rare to find defenses of, or support for, the practice of LPU, but Roth (1981) of the National Institute of Arthritis, Metabolism and Digestive Disorders presented a distinct point of view: "It is surprising if [journals] place the blame for multiple short papers on the authors. [Some] journals typically impose very harsh space limitations as a condition for publication, which is often independent of the true size of the scholarly work. Journal editors demand that we cut the baby in half and then lament the fragments that are produced!” (p. 212). Owen [a pseudonym] (2004) suggested support for LPU:

Another reason is that there are still those who do count beans. One thing I have learned as an administrator is that, while I may make the effort to discern quality in a faculty member's record, the further up the line the tenure or promotion package passes, the harder it is for administrators, or members of a faculty committee, to do that. Some don't even bother: When they look at this year's crop of tenure applicants, the one with six LPU's will stand out next to the one with a single major publication. The "numbers game" really does exist, often in unexpected pockets around the campus (p. C2).

Owen is countered, though, by Gherman (2004), who wrote in response:

The practice the essay describes is certainly alive and well in academe, but I hope Owen realizes that this practice has a direct impact on the institution's library budget. Publishing to get more items on one vita adds to the escalating costs of journals, and therefore leads to the cancellation of more journals and professors' access to an everdecreasing amount of scientific and scholarly literature. (p. A47)

Yet another commentator (Refinetti, 1990) defended the practice: “Although it may seem unimportant at first sight, the publication of small units makes it much easier for the reader to organize his/her database. Quanta of scientific information are much more easily stored and retrieved ... than more complex units of information” (p. 128). Refinetti's conclusion is questionable at best; a more compact database lends itself more readily to rapid and effective retrieval. Some journal editors (Brand, Heckman, \& Scott, 2005) explicated the problem clearly:

When only a limited amount of material is identical or similar, but much is not, we judge these to be cases of least publishable units. When either editor raises a question of closer similarity of the articles, we send blinded copies to expert independent reviewers for their opinion. Depending on whether those reviewers believe the articles would represent redundant publication, we take what we believe is appropriate action. 


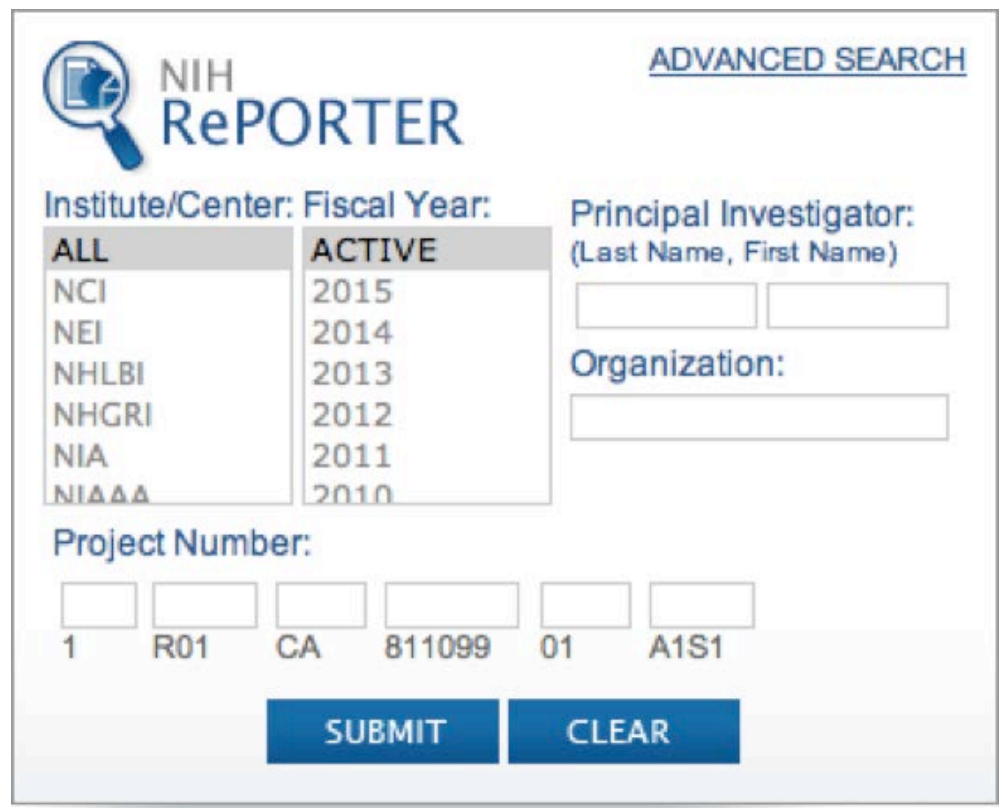

Figure 1. Search screen of eReporter database

We write to authors and ask for an explanation, remind them of potential misconduct, and request that the explanatory letter be signed by all authors. (p. 679)

\section{CONCEPTS OF SPECIALIST AND AMATEUR}

Information overload is indeed a dilemma for the world's scientific researchers; it may be the LPU which contributes to the problem. In order to investigate this possibility, the research articles in the January through March 2011 issues of the Journal of the American Medical Association (JAMA) and the New England Journal of Medicine were scanned. In particular, the acknowledgements were examined to determine whether any authors of the articles received funding from the U.S. National Institutes of Health (NIH). If there is an indication that one or more of the authors of the articles received such funding, the grant numbers were recorded. Those numbers were then searched by author and grant number in NIH's eReporter database. The NIH's eReporter database includes information regarding research projects funded by the NIH (National Institute of Health (NIH), 2012). The NIH's eReporter database was searched in order to verify the funding to the author. Figure 1 illustrates the eReporter database.

Next, Medline was searched by author for the individuals' publications from 2010 through 2013. Medline is a bibliographic database, which contains references to journal articles published in the discipline of life sciences with a concentration on biomedicine (U.S. National Library of Medicine, 2015). Every article in the publications list from Medline was checked to see if it indicates the work was funded by the same grant as is acknowledged in the source article in JAMA or the New England Journal of Medicine. The number of articles so funded was recorded, as was the total number of articles for the time period by each author. The working assumption is that publications specifying the same grant source are related closely by content and are indicators of LPU at work.

The January through March issues of both journals were examined and the results are reported in Table 1. 
Table 1. Publications by authors ${ }^{1}$

\begin{tabular}{|c|c|c|}
\hline Author \# & $\begin{array}{c}\text { Total Publications } \\
2010-2013\end{array}$ & $\begin{array}{c}\text { NIH Publications } \\
2010-2013\end{array}$ \\
\hline$\# 1$ & 31 & 5 \\
\hline$\# 2$ & 20 & 6 \\
\hline \#3 & 23 & 7 \\
\hline$\# 4$ & 41 & 7 \\
\hline \#5 & 49 & 7 \\
\hline \#6 & 56 & 7 \\
\hline \#7 & 95 & 7 \\
\hline$\# 8$ & 40 & 7 \\
\hline \#9 & 85 & 7 \\
\hline \#10. & 16 & 7 \\
\hline \#11 & 54 & 8 \\
\hline \#12. & 107 & 8 \\
\hline \#13 & 118 & 8 \\
\hline$\# 14$ & 42 & 8 \\
\hline \#15 & 77 & 9 \\
\hline \#16 & 51 & 10 \\
\hline \#17. & 86 & 10 \\
\hline \#18. & 170 & 10 \\
\hline \#19 & 67 & 11 \\
\hline \#20 & 60 & 12 \\
\hline \#21 & 34 & 12 \\
\hline \#22 & 20 & 13 \\
\hline \#23 & 20 & 14 \\
\hline \#24 & 86 & 14 \\
\hline \#25 & 48 & 16 \\
\hline \#26 & 75 & 16 \\
\hline$\# 27$ & 54 & 17 \\
\hline \#28 & 33 & 17 \\
\hline \#29 & 77 & 23 \\
\hline \#30 & 24 & 23 \\
\hline \#31 & 156 & 26 \\
\hline \#32. & 62 & 28 \\
\hline \#33 & 131 & 30 \\
\hline \#34 & 60 & 35 \\
\hline \#35 & 62 & 42 \\
\hline \#36 & 126 & 48 \\
\hline \#37 & 219 & 67 \\
\hline
\end{tabular}

${ }^{1}$ The authors are anonymized, on advice of the journal editor

Author ID numbers assigned by the researchers are listed in the first column. In the second column is the total number of articles for each author. The third column reports the number of publications acknowledging the NIH grant from the source article. Note that the number does not include the source article from JAMA or the New England Journal of Medicine.

The data presented in Table 1 point to some matters of possible concern for the global research community. Some of the issues echo the points made by commentators noted above. 
For one thing, these biomedical researchers are prolific; each has a substantial number of publications from 2010 through 2013. That, in itself, may not be surprising, since their work has been deemed worthy of support by NIH. Those publications also signal a huge literature that has to be searched in order to find work relevant to information seekers' needs. More importantly, each researcher has several publications arising from work funded by a single grant from the NIH.

As previously noted, Medline contains references to journal articles, so the actual number of publications reported in Table 1 from each author is likely much higher (due to other types of publications, for example conference presentations, reports, etc.). To reiterate some of the concerns expressed above, it is an open question whether science requires such a large number of publications to communicate the essential elements of the research findings of the scholars. If the large number is not required for communicative purposes, the literature may effectively be inflated by duplication of findings, or the parsing of findings into numerous pieces of work. Researchers all over the world must wade through the number of publications to piece together the meaning of these researchers' work.

\section{CONCLUSION}

Some of the works noted above hint that there is something wrong with LPU, or "salami" tactics, but other commentators are even more open in their criticism. The practice is sometimes connected with duplicate publication (which is recognized as a Medical Subject Heading). There may not be complete duplication inherent in LPU, but there is likely to be at least some duplication in the description of research aims, methods, and research design. Rohrich and Sullivan (2009) stated that such things "Clutter and 'contaminate' the scientific literature with redundant literature” (p. 1334). While the aim of the authors may be to disseminate their messages more widely, the result borders on misconduct since it makes it more difficult for readers of the literature to locate the full and complete results of a work. Rosenthal, Masdon, Buckman, and Hawn (2003) claimed, “The practice of ‘salami slicing' or reducing a given study to the smallest publishable units is. . . controversial and is not widely discussed. Most editorials addressing the issue of duplicate publications recognize that this practice is not considered unethical” (p. 774). Reid (2002) is unequivocal in his opinion of the practice of LPU: "publication of the 'least publishable unit' or 'salami science' where many papers are spun off from one data set” constitutes scientific misconduct (p. 239).

An ethical framework is provided by Jürgen Habermas throughout several of his writings. In his (1984) foundational work on communicative action, he wrote, "Intentionalist semantics is based on the counterintuitive idea that understanding the meaning of a meaning of a symbolic expression $X$ can be traced back to the intention of speaker $S$ to give the hearer $H$ something to understand by means of a sign” (pp. 274-75). LPU disrupts the process of making meaning because the speaker perverts the process of intentionalist semantics. The speaker does not intend to provide a clear sign from which the hearer can discern a clear message; the message is diffused across an enormous literature and the onus is placed on the hearer to make sense of an intentional distorted message. Habermas sums up the ethical responsibility of communication in a descriptive way when he (1990) articulated the principle of Universalisation: "(U) All affected can accept the consequences and the side effects of its general observance can be anticipated to have for the satisfaction of everyone's interests (and these consequences are preferred to those of known alternative possibilities for regulation)" (p. 65). This component of Habermas's discourse ethics is a pragmatic conception, intended to work and be workable in just about all settings. As demonstrated above by statements from 
Rosenthal et al. (2003) and Reid (2002), there is not a clear consensus in the scientific community regarding LPU and scientific misconduct. If editors and authors were to discuss what constitutes LPU and follow the principles they would be much more likely to identify the ethical difficulties inherent in LPU.

The impact on academic libraries of LPU practices is palpable. Sue Wiegand (2013) wrote that the challenge for libraries is "to reinvent the role of serials in the scholarly communication discovery process, and to use the resulting knowledge and librarian expertise to form convivial connections with faculty who are intrigued by the transformation of scholarly communication” (p. 336). The notion of such a challenge assumes there are inherently similar goals between the two groups-librarians and scholars. On the other hand, Colin Steele (2014) said that, "Librarians need to be more involved in the [scholarly communication] process, even if it is more advocacy than the direct exercise of political power" (p. 251). There is a political element in play with the LPU practice; it is accepted that more publications will be of greater benefit to the faculty member than fewer publications. Perhaps more importantly, the working assumption—and this assumption appears to hold both for faculty and for administrators-is that there should be effort to produce maximum numbers of publications, rather than optimum numbers. The political environment of higher education has a responsibility to address this assumption.

One additional problem will be mentioned here, but will not be discussed in detail. The number of publications is almost inevitably going to affect the process of information retrieval for researchers. That is, if researcher $\mathrm{A}$ is searching the literature for works on a certain topic, and the practice of LPU obtains, then researcher A may retrieve many more articles than would be intentionally informative. That researcher may either take a great deal of time to sort through the works in order to locate the gist of the research that has taken place, or may simply cite all, or many, of the articles retrieved as a means of covering bases. Citations to the LPU author's work might be inflated by this process, which becomes important if faculty at universities include citation counts in evaluation.

As is evident from the above, the practice of LPU does appear to have empirical support, and it can have potentially deleterious effects on the literature and for all seekers of research reporting. It is a phenomenon that deserves attention and should be formally addressed by the gatekeepers of the scientific literature. Future research should examine perceptions of LPU by researchers such as those authors examined in this study. Additionally, a more thorough examination of the occurrences of actual types of LPU (e.g. salami slices, overlaps, stylistic re-writes) will contribute to a better understanding of how LPU is manifested in scholarly research.

\section{REFERENCES}

Angell, M. (1986). Publish or perish: A proposal. Annals of Internal Medicine, 104(2), 261262.

Brand, R. A., Heckman, J. D., \& Scott, J. (2004). Changing ethical standards in scientific publication. Journal of Bone \& Joint Surgery, 86-B(7), 937-938.

Brand, R. A., Heckman, J. D., \& Scott, J. (2005). Letter. Journal of Bone \& Joint Surgery, 87-A(3), 679.

Broad, W. J. (1981). The publishing game: Getting more for less. Science, 211(4487), 113739.

Broad, W. J., \& Wade, N. (1982). Betrayers of the truth: Fraud and deceit in the halls of science. New York: Simon \& Schuster. 
Buddemeier, R. W. (1981). Least publishable unit. Science, 212, 494.

Dupps, W. J., \& Randleman, J. B. (2012). The perils of the least publishable unit. Journal of Cataract \& Refractive Surgery, 38(9), 1517-1518.

Gherman, P. M. (2004). Faculty members and publishable units. Chronicle of Higher Education, 50(29), A47.

Gleeson, M., \& Biddle, S. (2000). Duplicate publishing and the least publishable unit. Journal of Sports Medicine, 18, 227-228.

Goldsborough, R. (2009). Battling information overload in the information age. Tech Directions, 68(9), 13.

Habermas, J. (1984) Theory of communicative action: Volume one. (T. McCarthy, Trans.). Boston: Beacon Press.

Habermas, J. (1990). Moral consciousness and communicative action. (C. Lenhardt \& S.W. Nicholsen, Trans.). Cambridge, MA: MIT Press.

Huth, E. J. (1996). Irresponsible authorship and wasteful publication. Annals of Internal Medicine, 104, 257-259.

National Institute of Health. (2012). About RePORTER data. In RePORTER frequently asked questions. Retrieved from http://report.nih.gov/faq.aspx?sid=2\#36

Owen, W. J. (2004). In defense of the least publishable unit. Chronicle of Higher Education, 50(23), C1-C4.

Refinetti, R. (1990). In defense of the least publishable unit. FASEB Journal, 4, 128-129.

Reid, T. (2002). Canadian Family Physician's new ethics guidelines. Canadian Family Physician, 48(2), 238-240.

Rohrich, R. J., \& Sullivan, D. (2009). Plagiarism and dual publication: Review of the issues and policy statement. Plastic and Reconstructive Surgery, 124(4), 1333-1339.

Rosenthal, E. L., Masdon, J. L., Buckman, C., \& Hawn, M. (2003). Duplicate publication in the otolaryngology literature. Laryngoscope, 113(5), 772-773.

Roth, J. (1981). Letter. Science, 212, 494.

Steele, C. (2014). Scholarly communication, scholarly publishing, and university libraries. Plus ça change? Australian Academic \& Research Libraries, 45(4), 241-261.

Trimble, S. W., Grody, W. W., McKelvey, B., \& Gad-el-Hak, M. (2010). The glut of academic publishing: A call for a new culture. Academic Questions, 23, 276-286.

U.S. National Library of Medicine. (2015). Fact sheet: Medline. Retrieved from https://www.nlm.nih.gov/pubs/factsheets/medline.html

Wiegand, S. (2013). Beginning the conversation: Discussing scholarly communication. The Serials Librarian, 65, 335-349.

Yankauer, A. (1990). Editor's report: Scientific misconduct and the responsibility of journal editors. American Journal of Public Health, 80(4), 399-400. 